\title{
ANATOMIA DA MADEIRA DE ACACIA DECURRENS Willd. ${ }^{1}$
}

\author{
JOSÉ NEWTON CARDOSO MARCHIORI ${ }^{2}$
}

\section{RESUMO}

São anatomicamente descritos os caracteres gerais, macroscópicos e microscópicos da madeira de Acacia decurrens Willd., com base em amostras sul-brasileiras. Ao microscópio, a espécie em estudo separa-se das madeiras nativas do subgênero Acacia Vassal pelo parênquima axial pouco abundante, composto por séries de $2-4$ células. Com relação às espécies nativas do subgênero Aculeiferum Vassal, Acacia decurrens distinguese pela ausência de fibras septadas na madeira.

Palavras-chave: Anatomia da madeira, Acacia decurrens Willd., Racosperma decurrens (Willd.) Pedley, série Botryocephalae Bentham, sub-gênero Heterophyllum Vassal.

\section{SUMMARY}

\section{[Wood anatomy of Acacia decurrrens Willd.].}

The general, macroscopic and microscopic features of the wood of Acacia decurrens Willd. are described, based on south brazilian samples. Under microscope, the material examined can be easily separated from native species of subgenus Acacia Vassal for having less abundant axial parenchyma, in series with $2-4$ cells. Compared with native species of subgenus Aculeiferum Vassal, Acacia decurrens can be distinguished by the absence of septate fibres in the wood.

Key words: Wood anatomy, Acacia decurrens Willd., Racosperma decurrens (Willd.) Pedley, series Botryocephalae Bentham, subgenus Heterophyllum Vassal.

\section{INTRODUÇÃO}

A literatura anatômica sobre o gênero Acacia (Tourn.) Mill. contrasta, por sua exigüidade, com a importância econômica e diversidade de espécies nativas e cultivadas no continente americano. Record \& Hess (1949), por exemplo, não fazem qualquer referência ao mesmo em seu clássico Timbers of the New World, a despeito das numerosas espécies nativas e cultivadas nas três Américas ${ }^{3}$.

Árvore inerme e de porte médio, Acacia decurrens Willd. insere-se na série Botryocephalae (Bentham, 1875), ou no subgênero

1 Recebido em 11-3-2009 e aceito para publicação em 21-12-2009.

2 Engenheiro Florestal, Dr. Bolsista de Produtividade em Pesquisa (CNPq - Brasil). Professor Titular do Departamento de Ciências Florestais, Universidade Federal de Santa Maria. Santa Maria, RS, Brasil.

3 Sobre este ponto, Rico-Arce (2007) refere a ocorrência de 159 espécies nativas e cultivadas nas três Américas, bem como cerca de 52 táxones infraespecíficos.
Heterophylllum (Vassal, 1972). Originária do leste da Austrália, nos estados de Nova Gales do Sul e Queensland (Ewart, 1930), a espécie foi introduzida no Brasil como árvore ornamental e para a produção de tanino, à semelhança da acácia-negra verdadeira (Acacia mearnsii De Willd.). Rico-Arce (2007) informa que a espécie, de rápido crescimento e múltiplas finalidades, tem grande potencial invasor nos Neotrópicos, necessitando de erradicação em algumas áreas. Em sua pátria de origem, recebe os nomes comuns de "early black wattle", "green wattle", "Sydney black wattle", "king wattle" e "queen wattle". Para o Uruguai, Herter (1930) indica o nome de "aroma". Rico-Arce (2007), por sua vez, refere que a espécie é conhecida como "carbonero", na América Central.

No Rio Grande do Sul, Acacia decurrens é geralmente confundida com a acácia-negra verdadeira, cabendo lembrar, todavia, que sua casca possui teor de tanino mais baixo do que a Acacia mearnsii (Mattos, 1980). 
Das espécies australianas introduzidas no sul do Brasil, foram anatomicamente descritas as madeiras de Acacia mearnsii, Acacia longifolia, Acacia podalyriaefolia e Acacia melanoxylon.

Para Acacia mearnsii De Willd., Costa \& Marchiori (1980) salientam: fibras libriformes não septadas; parênquima axial escasso (menos de $20 \%$ do volume da madeira), em séries de 2 - 4 células; raios com até 4 células de largura; e poros com frequiência de $8-17-34 / \mathrm{mm}^{2}$.

No caso de Acacia longifolia, Illana \& Marchiori (1980) registram: fibras libriformes não septadas; parênquima axial em séries de 2 - 4 células, compondo menos de $20 \%$ do volume da madeira; raios pouco numerosos, por vezes com mais de 4 células de largura; vasos com frequiência superior a $16 / \mathrm{mm}^{2}$; e fibras muito curtas, com menos de $1000 \mu \mathrm{m}$ de comprimento.

Para Acacia podalyriaefolia, Marchiori (2010a) relaciona: fibras libriformes não septadas; parênquima axial pouco abundante, em séries parenquimáticas de $2-4$ células; e raios de até 3 células de largura.

Para a madeira de Acacia melanoxylon, Marchiori (2009) destaca os seguintes aspectos anatômicos: fibras libriformes não septadas; parênquima axial pouco abundante, em séries de 2 - 4 células; raios numerosos a muito numerosos (5 - 9,5 - 15/mm), com mais de 4 células de largura; e freqüência de poros inferior a $13 / \mathrm{mm}^{2}$.

$\mathrm{O}$ presente trabalho visa à descrição dos caracteres gerais, macroscópicos e microscópicos da madeira de Acacia decurrens, bem como a sua distinção de espécies afins, com base na anatomia da madeira.

\section{MATERIAL E MÉTODOS}

O material estudado consiste de 5 amostras de madeira, conservadas nas xilotecas da Universidade Federal do Paraná (UFPR), do Instituto de Pesquisas Tecnológicas de São Paulo (IPT) e do Herbário do Departamento de Ciên- cias Florestais da Universidade Federal de Santa Maria (HDCF), com os seguintes registros:

- HDCF 103. Granja, A., s.n. (25-10-1981). TANAC Florestal, Montenegro, RS. Flores. UFPR 1112. Col. Marchiori n. 206.

- HDCF 105. Granja, A., s.n. (25-10-1981). TANAC Florestal, Montenegro, RS. UFPR 1134. Col. Marchiori n. 214.

- IPT 5883. Rem.: Manoel Silva Neto, 1950. Instituto de Tecnologia do Rio Grande do Sul.

- IPT 3698. Rem. D. Bento Pickel, Seção de Introdução de Essências, Serviço Florestal, São Paulo, Capital. UFPR 1276.

- HDCF 8. Longhi \& Marchiori, s.n. (01.10.1980). Cerrito, Santa Maria, RS.

De cada amostra foram preparados três corpos-de-prova, orientados para a obtenção de cortes anatômicos nos planos transversal, longitudinal radial e longitudinal tangencial, respectivamente. Para a microtomia, os corpos-deprova foram previamente amolecidos por fervura em água e seccionados em micrótomo de deslizamento, regulado para a obtenção de cortes anatômicos com espessura nominal de 18 $\mu \mathrm{m}$. Os cortes foram tingidos com acridina-vermelha, crisoidina e azul-de-astra (Dujardin, 1964), desidratados em série alcoólica crescente $(25 \%, 50 \%, 75 \%, 90 \%, 95 \%$, duas vezes álcool absoluto), banhados em xilol e montados em lâminas permanentes, com "Entellan". Na confecção de lâminas de macerado seguiu-se a técnica de Jeffrey (Freund, 1970), usando-se coloração com safranina e o mesmo meio de montagem anteriormente referido.

A terminologia, número de medições e descrição da estrutura anatômica segue as recomendações da Copant (1973), com as modificações introduzidas por Burger (1979). Para as determinações estereológicas da percentagem de vasos, parênquima axial, raios e fibras, bem como da percentagem das classes de raios quanto à largura em número de células, seguiu-se a 
metodologia recomendada por Marchiori (1980). A cor da madeira foi determinada por comparação, usando-se a "Tabela de Cores para Solos" (Munsell, 1971), sob iluminação natural. As fotomicrografias foram tomadas em aparelho Carl Zeiss, com diferentes aumentos.

\section{DESCRIÇÃO DA MADEIRA}

\section{Caracteres gerais:}

Cerne e alburno distintos; alburno estreito, róseo-esbranquiçado (HUE 7.5 YR 8/2) e cerne rosado (HUE 7.5 YR 7/4). Madeira de grã direita, brilhante, moderadamente dura, não aromática, de textura média, com figura homogênea e escassa variação cromática.

\section{Caracteres macroscópicos:}

Parênquima axial: visível a olho nu, pouco abundante, em arranjo paratraqueal vasicêntrico.

Raios: invisíveis a olho nu em plano transversal, finos, pouco freqüentes; em plano longitudinal tangencial, visíveis a olho nu, baixos não estratificados. Espelhado, não contrastado no alburno; pouco contrastado no cerne.

Poros: visíveis a olho nu, pequenos, numerosos e em distribuição difusa, uniforme. Poros solitários e em múltiplos radiais de 2 a 4 . Linhas vasculares retilíneas, por vezes obstruídas com conteúdo escuro, no cerne.

Camadas de crescimento: distintas, individualizadas por zonas fibrosas tangenciais mais escuras.

Outros caracteres: canais secretores axiais, máculas medulares, líber incluso e canais secretores horizontais, ausentes.

\section{Caracteres microscópicos:}

Vasos: numerosos $\left(7-17-34 / \mathrm{mm}^{2} ; \mathrm{s}=\right.$ $5,38)$, representando $17 \%$ da seção transversal da madeira. Distribuição difusa, uniforme (Figura 1A,B). Poros solitários e em múltiplos de 2 a 8 , agrupados radialmente e em cachos (Figura 1B). Poros solitários, de diâmetro médio
$(80-122-155 \mu \mathrm{m} ; \mathrm{s}=16,73)$, com placas de perfuração simples, transversais ou ligeiramente oblíquas (Figura 1D). Apêndices curtos (20$66-188 \mu \mathrm{m} ; \mathrm{s}=33,90)$, presentes em uma (Figura 1D) ou em ambas as extremidades. Espessamentos espiralados, ausentes. Pontoações intervasculares alternas, arredondadas ou poligonais devido à proximidade das mesmas, de diâmetro pequeno a médio $(5,5-9-9 \mu \mathrm{m} ; \mathrm{s}$ $=0,77$ ), ornamentadas e com abertura horizontal, lenticular, inclusa ou coalescente a $2-3$ pontoações. Pontoações raio-vasculares pequenas $(4,5-5,6-8 \mu \mathrm{m} ; \mathrm{s}=0,80)$ e arredondadas. Pontoações parênquimo-vasculares pequenas (5 $-6-7,5 \mu \mathrm{m} ; \mathrm{s}=0,71)$, semelhantes às raiovasculares. Conteúdo com aspecto de gomo-resina, abundante em poros do cerne.

Parênquima axial: ocupando $8,3 \%$ do volume da madeira, em disposição nitidamente paratraqueal-vasicêntrica (Figura 1B,C). Células fusiformes, raras; de $232-434-548 \mu \mathrm{m}$ de altura $(\mathrm{s}=108,83)$ e $10-13-16 \mu \mathrm{m}$ de largura $(\mathrm{s}=2,58)$. Séries axiais de $227-413-783 \mu \mathrm{m}$ de altura $(\mathrm{s}=88,42)$ e $10-21-39 \mu \mathrm{m}$ de largura $(\mathrm{s}=7,14)$, compostas de $2-3-4$ células $(\mathrm{s}=$ $0,88)$. Cristais romboédricos de oxalato de cálcio com cerca de $20 \mu \mathrm{m}$ de comprimento, em séries de $14-18$ câmaras, principalmente no lenho tardio (Figura 1B; 2D).

Raios: pouco freqüentes a pouco numerosos (3-5-7/mm; $\mathrm{s}=0,92)$, representando $6,9 \%$ do volume da madeira. Tecido radial homogêneo, composto inteiramente de células horizontais (Figura 2A, B). Células de contorno elíptico, em plano longitudinal tangencial (Figura 2D). Raios agregados e fusionados, ausentes. Raios unisseriados, escassos (5,4\% do total); muito baixos $(17-85-250 \mu \mathrm{m} ; \mathrm{s}=42,02)$, extremamente finos $(4-9-18 \mu \mathrm{m} ; \mathrm{s}=3,07)$ e com 1 $5-17$ células de altura $(s=2,80)$. Os multisseriados, em sua maioria trisseriados (54,9\% do total), com numerosos bisseriados $(37,8 \%)$ e raros tetrasseriados $(1,9 \%)$; são bai$\operatorname{xos}(58-346-768 \mu \mathrm{m} ; \mathrm{s}=143,71)$ e muito 

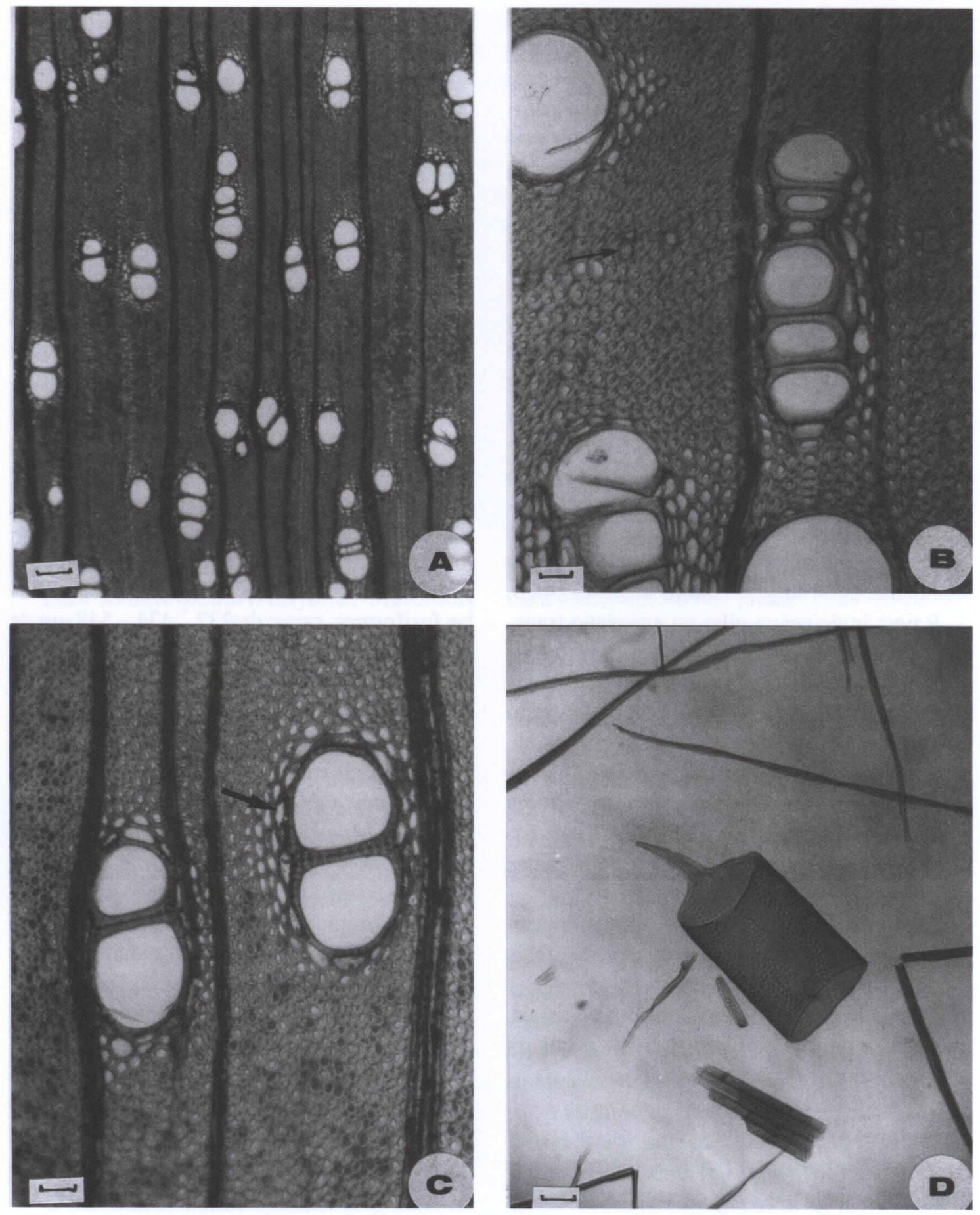

FIGURA 1 - Aspectos anatômicos da madeira de Acacia decurrens Willd. A-Seção transversal, destacando a distribuição e arranjo de poros. B - Seção transversal em limite de anel de crescimento, mostrando poros em múltiplos radiais e racemiformes, parênquima paratraqueal e concentração de cristais no término do anel (seta). C-Parênquima paratraqueal vasicêntrico (seta), em seção transversal. D - Elemento de vaso com placas de perfuração simples e apêndice em uma das extremidades. Escalas: $100 \mu \mathrm{m}$ (A); $25 \mu \mathrm{m}$ (B,C); $40 \mu \mathrm{m}$ (D). 

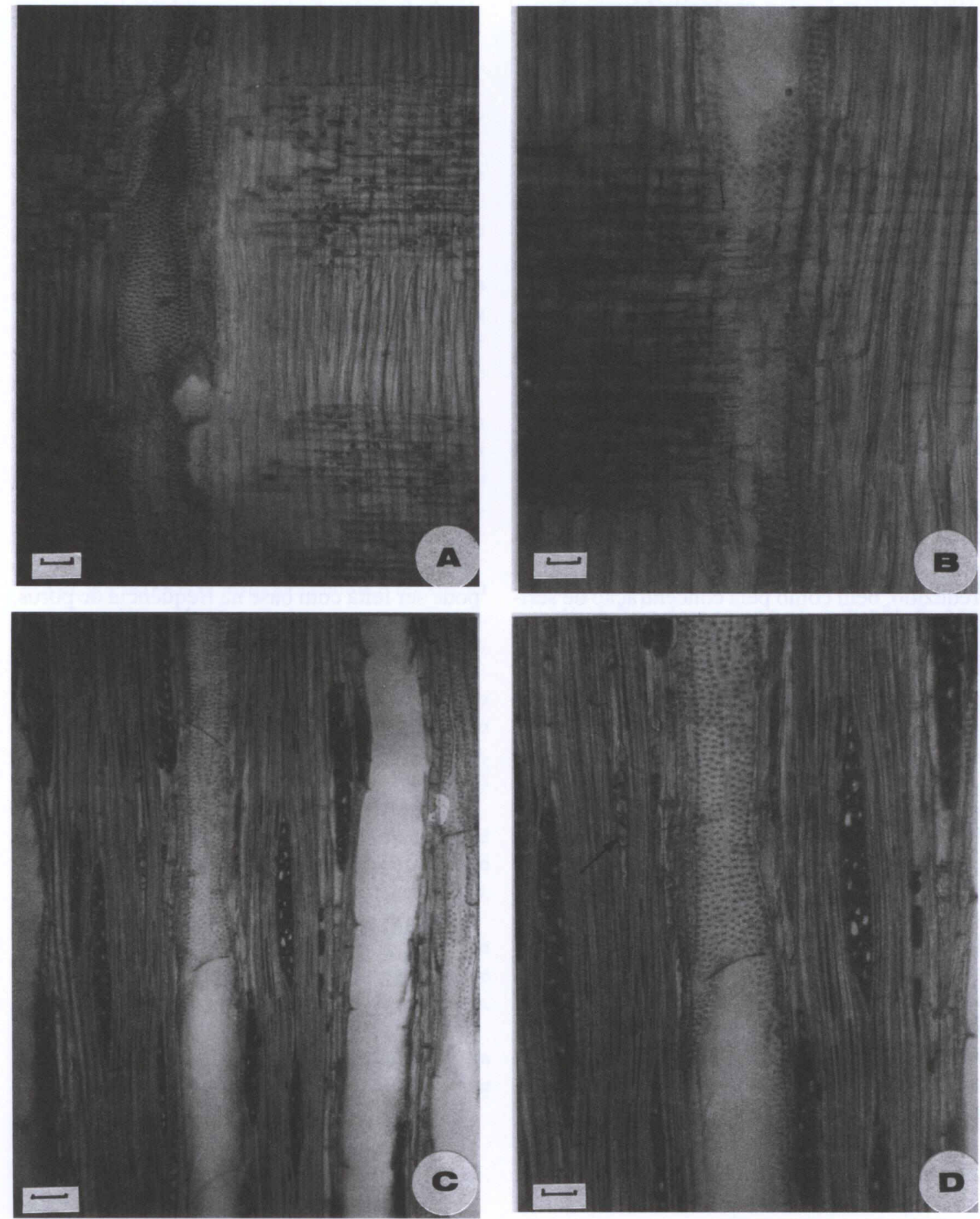

FIGURA 2 - Aspectos anatômicos da madeira de Acacia decurrens Willd. A - Raios homogêneos, elementos vasculares e fibras, em seção longitudinal radial. B - Estrutura radial homogênea e fibras não septadas, em seção longitudinal radial. C-Aspecto geral da madeira, em seção longitudinal tangencial. D - Raios multisseriados e séries axiais cristalíferas (seta), em seção longitudinal tangencial. Escalas: $40 \mu \mathrm{m}$ (A,C); $25 \mu \mathrm{m}$ (B,D). 
finos $(5-20-28 \mu \mathrm{m} ; \mathrm{s}=4,31)$, com $5-24-$ 57 células $(s=10,56)$ de altura (Figura 2C, D). Células cristalíferas, envolventes, eretas, esclerosadas, latericuliformes, oleíferas e quadradas, ausentes; conteúdo com aspecto de gomo-resina, abundante.

Fibras: proeminentes, ocupando $67,8 \%$ do volume da madeira $(s=3,56)$. Fibras libriformes, não septadas e frequentemente gelatinosas, com pontoações simples diminutas, mais numerosas nas faces radiais da parede. Fibras curtas (1000 $-1216-1420 \mu \mathrm{m} ; \mathrm{s}=101,72)$, estreitas $(9-14$ $-23 \mu \mathrm{m} ; \mathrm{s}=2,56)$ e de paredes espessas $(2,5-$ $4-6,3 \mu \mathrm{m} ; \mathrm{s}=0,84)$.

Outros caracteres: canais secretores, tubos laticíferos e taniníferos, líber incluso, máculas medulares e estratificação, ausentes. Anéis de crescimento distintos, marcados por lenho tardio com fibras radialmente estreitas e lúmen reduzido, bem como pela concentração de séries cristalíferas no limite do anel (Figura 1B).

\section{ANÁLISE DA ESTRUTURA ANATÔMICA}

Incluída na série Botryocephalae (Bentham, 1875) ou no subgênero Heterophyllum (Vassal, 1972), a madeira de Acacia decurrens Willd. separa-se facilmente das espécies nativas no sul do Brasil. Com relação à Acacia caven (Molina) Molina $^{4}$, o bem conhecido "espinilho" (Marchiori, 1992), bem como à Acacia ibirocayensis Marchiori ${ }^{5}$ (Marchiori, 1993) e a Vachellia farnesiana (L.) Wight \& Arn. ${ }^{6}$ (Marchiori 2010b), todas pertencentes ao subgênero Acacia Vassal, o material em estudo distingue-se por ter parênquima axial pouco abundante (até $20 \%$ do volume da madeira), composto por séries de $2-4$ células.

De Acacia bonariensis (Marchiori, 1996), Acacia nitidifolia (Marchiori, 1991a), Acacia

${ }^{4}$ A espécie tem sido referida, ultimamente, como Vachellia caven (Molina) Seigler \& Ebinger.

5 O mesmo que Vachellia ibirocayensis (Marchiori) Deble \& Marchiori.

${ }^{6}$ Na literatura mais antiga, a espécie é referida como Acacia farnesiana (L.) Willd. plumosa (Marchiori 1991b), Acacia recurva (Marchiori, 1982), Acacia tucumanensis (Marchiori 1994) e Acacia velutina (Marchiori, 1995), Acacia decurrens separa-se pela ausência de fibras septadas na madeira.

A madeira de Acacia decurrens assemelhase a outras espécies australianas cultivadas no sul do Brasil (A. podalyriaefolia, A. dealbata, A mearnsii, A. melanoxylon), seja pela ausência de fibras libriformes septadas, seja pelo parênquima axial pouco abundante (até 20\%). De Acacia podalyriaefolia (Marchiori, 2010a), o material em estudo separa-se por ter raios com mais de 3 células de largura. Comparado a Acacia dealbata (Marchiori, 1990) e A. mearnsii (Costa \& Marchiori, 1980), Acacia decurrens distingue-se por ter raios mais largos, com mais de 4 células de largura. Comparado a Acacia melanoxylon (Marchiori, 2009), a distinção pode ser feita com base na frequiência de poros, posto que o caráter é nitidamente mais abundante na espécie presentemente descrita ( $>16 /$ $\mathrm{mm}^{2}$ ). Comparada a Acacia longifolia (Illana \& Marchiori, 1980), finalmente, a diferenciação requer o exame do comprimento de fibras, pois ultrapassa a $1000 \mu \mathrm{m}$ nesta espécie e fica abaixo deste valor em Acacia decurrens.

\section{REFERÊNCIAS BIBLIOGRÁFICAS}

BENTHAM, G. Revision of the sub-order Mimoseae. Trans. Linn. Soc. London, n. 30, p. 335-664, 1875.

BURGER, L.M. Estudo anatômico do xilema secundário de sete espécies nativas do gênero Dalbergia, Leguminosae Faboideae. Curitiba: UFPR, 1979. 184 f. Dissertação (Mestrado em Engenharia Florestal) - Universidade Federal do Paraná.

COPANT. Comissão Panamericana de Normas Técnicas. Descrição macroscópica, microscópica e geral da madeira - Esquema I de recomendação. Colômbia, 1973. 19 p. (COPANT 30).

COSTA, A.F. da; MARCHIORI, J.N.C. Estudo anatômico da madeira de Acacia mearnsii De Willd. In: Anais do IV Congresso Florestal Estadual. Nova Prata, RS, 1980. p. 237-245. 
DUJARDIN, E.P. Eine neue Holz-Zellulosenfaerbung. Mikrokosmos, n. 53, p. 94, 1964.

EWART, A.J. Flora of Victoria. Melbourne: H.J. Greeen, 1930. 1527 p.

FREUND, H. Handbuch der Mikroskopie in der Technik. Frankfurt: Umsham Verlag, 1970.379 p.

HERTER, G. Estudios botánicos en la región uruguaya. IV. Florula uruguayensis Plantae vasculares. Montevideo: Ministerio de Industrias, 1930. $191 \mathrm{p}$.

ILLANA, H.A.; MARCHIORI, J.N.C. Estudo anatômico do xilema secundário de Acacia longifolia (Andr.) Willd. In: Anais do IV Congresso Florestal Estadual. Nova Prata, RS, 1980. p. 207-215.

MARCHIORI, J.N.C. Estudo anatômico do xilema secundário de algumas espécies dos gêneros Acacia e Mimosa, nativas no estado do Rio Grande do Sul. Curitiba: UFPR, 1980. $186 \mathrm{f}$. Dissertação (Mestrado em Engenharia Florestal) - Universidade Federal do Paraná.

MARCHIORI, J.N.C. Estudo anatômico do xilema secundário e da casca de Acacia recurva Benth. (Leguminosae Mimosoideae). Ciência e Natura, Santa Maria, v. 4, p. 95-105, 1982.

MARCHIORI, J.N.C. Anatomia das madeiras do gênero Acacia, nativas e cultivadas no estado do Rio Grande do Sul. Curitiba: UFPR, 1990. 226 f. Tese (Doutorado em Ciências Florestais) - Universidade Federal do Paraná.

MARCHIORI, J.N.C. Anatomia da madeira de Acacia nitidifolia Speg. (Leguminosae Mimosoideae). Ciência Florestal, Santa Maria, v. 1, n. 1, p. 46-63, 1991a.

MARCHIORI, J.N.C. Anatomia da madeira de Acacia plumosa Lowe (Leguminosae Mimosoideae). Ciência e Natura, Santa Maria, v. 13 , p. $67-77,1991$ b.

MARCHIORI, J.N.C. Anatomia da madeira e casca do espinilho, Acacia caven (Mol.) Mol. Ciência
Florestal, Santa Maria, v. 2, n. 1, p. 27-47, 1992.

MARCHIORI, J.N.C. Estudo anatômico do xilema secundário de Acacia ibirocayensis Marchiori (Leguminosae Mimosoideae). Ciência e Natura, Santa Maria, n. 15, p. 149-159, 1993.

MARCHIORI, J.N.C. Anatomia da madeira e casca de Acacia tucumanensis Gris. Ciência e Natura, Santa Maria, n. 16, p. 85-104, 1994.

MARCHIORI, J.N.C. Anatomia da madeira e casca de Acacia velutina DC. Ciência e Natura, Santa Maria, n. 17, p. 99-114, 1995.

MARCHIORI, J.N.C. Anatomia da madeira de Acacia bonariensis Gill. ex Hook. \& Arn. Ciência Rural, Santa Maria, v. 26, n. 2, p. 209-216, 1996.

MARCHIORI, J.N.C. Anatomia da madeira de Acacia melanoxylon R. Br. Balduinia, Santa Maria, n. 18, p. 26-32, 2009.

MARCHIORI, J.N.C. Anatomia da madeira de Acacia podalyriaefolia A. Cunn. Balduinia, Santa Maria, n. 20, p. 10-15, 2010a.

MARCHIORI, J.N.C. Anatomia da madeira de Vachellia farnesiana (L.) Wight \& Arn. Balduinia, Santa Maria, n. 22, p. 9-14, 2010 b.

MATTOS, N.F. Espécies conhecidas como "acácia negra”, cultivadas no Rio Grande do Sul. Roessléria, v. 3, n. 2, p. 67-79, 1980.

MUNSELL COLOR DIVISION. Soil color charts. Baltimore, 1971, s.p.

RECORD, S.J.; HESS, R.W. Timbers of the New World. New Haven: Yale University Press, 1949. $640 \mathrm{p}$.

RICO-ARCE, M. de L. American species of Acacia. México: Comisión Nacional para el Conocimiento y Uso de Biodiversidad (CONABIO), 2007. 207 p.

VASSAL, J. Ontogenetic and seed research applied to the morphological, taxonomical and phylogenetic study of the genus Acacia. Travaux Lab. For. Toulouse, v. 1, n. 8, p. 1-125, 1972. 